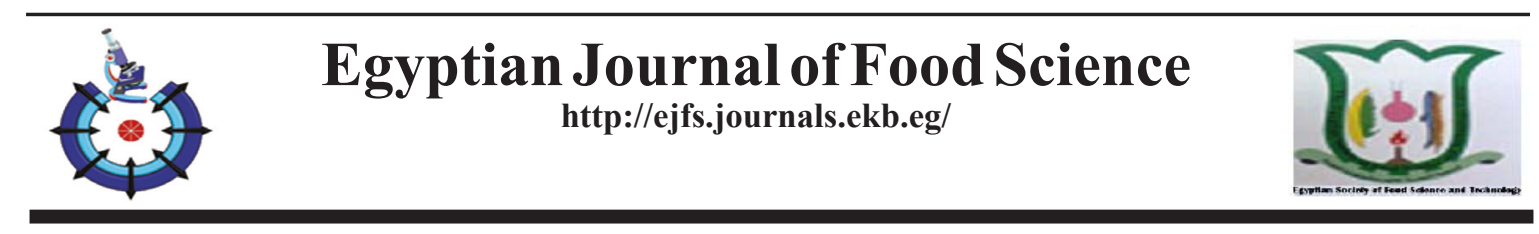

\title{
Date Seed Oil as A Potential Natural Additive to Improve Oxidative Stability of Edible vegetable Oils
}

\author{
Eman M. A. Taha ${ }^{*}$, Naglaa, A. A. Abd-Elkarim ${ }^{1}$,Zienab F. R. Ahmed ${ }^{2,3}$ \\ ${ }^{1}$ Department of Food Science, South Valley University, Qena 83523, Egypt \\ ${ }^{2}$ Department of Horticulture, South Valley University, Qena 83523, Egypt \\ ${ }^{3}$ Department of Integrative Agriculture, United Arab Emirate University, Al Ain, \\ $15551 U A E$
}

\begin{abstract}
C CIENTISTS warn against the dangers of frying food in oil as it releases toxic chemicals linked to cancer and heart disease. The negative effects of synthetic antioxidants lead to searching for a substitute with natural resources. In the present study, fruits of three date palm cultivars; 'Hayani', 'Sewi' and 'Sakouti', were collected at mature stage and date seeds were used for oil extraction. Chemical properties of the oil as well as rancimate measurements were measured to determine the oxidative stability of the oil. Different levels $(5,10.15 \%)$ of date seed oil were added to crude soybean oil and the oxidative stability for the mixer were then compared to the commercial soybean oil with BHT additive. Pit powder oil content ranged from 8.2-10.6.'Sewi' had the highest total phenols content of phenolic compounds that 183.92 $\mathrm{mg}$ among cultivars, while carotenoids content varied $(33.5-88.5 \mathrm{mg} / \mathrm{kg})$. The fatty acid compositions of all the cultivars were very similar. Rancimat measurements for all cultivars' oil were higher than that of crude soybean oil. Date seed oil addition at different levels to soybean crude oil increased the rancimat induction time. Treatment of 'Sewi' oil at $15 \%$ was the best treatment among cultivars and was higher than that of the synthetic BHT effect. The results suggested that the seeds from the examined date cultivars as byproducts are good source of oil with high quality that may efficiently used as a natural additive to promote the oxidative stability of other vegetable oil.
\end{abstract}

Keywords: Date seed oil, Natural antioxidant, Heat stability

\section{Introduction}

Date seed is a byproduct of date fruit industry. Previous studies found that date seed are an excellent source of dietary fiber, and has protein and minerals as well as about $8-15 \%$ oil (Herchi et al., 2014). Physicochemical characteristics and antioxidant activity of both seed and flesh oil of the date showed that they posse functional properties in the food industry (Herchi et al., 2014). Based on the fatty acid composition of date seed oil, it is suggested the use of this oil for nutritional purpose, as edible cooking oil due to the high stability and resistance of date seed oil to heat treatment which indicate the good storability of this oil. Moreover, different degree of unsaturated fatty acids of date seed oil compared to other vegetable oil make it as potential oil that can be developed for different uses.

During frying process the oil release high concentrations of chemicals called aldehydes, and lead to oil oxidation which have been linked to illnesses including cancer, heart disease and dementia(Grootveld et al., 2001). It is difficult to implement any regulation against the use of this frying oil in the restaurant to increase the safety and quality of fried foods (Paul and Mittal, 1997). In most countries, synthetic antioxidant compounds are added to the food such as oil in order to prolong product shelf life. Antioxidants are components which prevent auto-oxidation of oils and fats occur during cooking and responsible for rancid odors and flavors which reduces nutritional

"Corresponding author :Tel: 01127702677. Email : e.taha@agr.svu.edu.eg

Received:21/5/2019; accepted:17/10/2019

DOI: 10.21608/EJFS.2019.13050.1007

(C)2019 National Information and Documentation Centre (NIDOC) 
quality of the oil (Young and Woodside, 2001). Synthetic Antioxidants such as butylated hydroxyl anisole (BHA), propyl gallate (PG), tertbutyl hydroquinone (TBHQ) and butylated hydroxyl toluene (BHT), are the most frequently used. The level of synthetic antioxidants is regulated and the safety has been tested, however there is always argument because of their possible toxic effects during long-term intake and possibility of being harmful Shahidi (2005). Currently, there is a strong trend to search for an efficient natural source of antioxidants to minimize or avoid the use of synthetic food additives and minimizing damage to our cells (Yanishlieva \& Marinova, 2001, Shebis et al., 2013 and Taghvaei \& Jafari, 2015).

Recent studies reported that natural antioxidants showed greater anti-oxidant efficiency than synthetic antioxidants Sarkar (2016). Therefore, the use of natural plant extracts; such as olive plant, green tea, sesame, medicinal plants, with antioxidant activities in various edible oils have been tested (Bouaziz et al., 2008, Taha et al., 2014, Leonardis et al., 2007, Suja et al., 2004, Bozkurt, 2006 and Bandak et al., 2011). These natural antioxidants compounds were able to improve the oxidation stability of the vegetable edible oil.

The reports on date seed oil as a source of antioxidants is limited, therefore more research should be conducted to provide evidence for developing of edible products (Abdul Afiq et al., 2013 and Nehdi et al., 2010). The main objective of this study was to reduce the use of synthetic antioxidantsin the edible oilby using seed oil of three well known varieties of date palm as a source of natural antioxidant to promote the oxidative stability of the crud soybean oil.

\section{Materials and Methods}

Plant materials preparation and oil extraction

Three date palm cultivars; grown in southern Egypt were used in this study. Randomly, fruits from soft cultivar 'Hayani', semi-dry cultivar 'Sewi' and dry cultivar 'Sakouti' at ripe stage, were collected. Fruits were washed with bleach, rinsed three times with distilled water and patted dry. Uniform group of fruits was subjected to physical evaluation such as: fruits weight, date flesh and pit weight, flesh and pit percentage and ration, and chemical measurements such as moisture contents, total soluble solids (TSS), titratable acidity and $\mathrm{pH}$ of the pulp juice. The other group of fruits was cleaned and their pits were separated using sharp knife edge. Pits were then dried using an air oven dryer at $70^{\circ} \mathrm{C}$ for $24 \mathrm{hr}$, and milled with a hammer mill and sieved to obtain a fine pit powder for further use. The moisture, oil and ash contents of the pit powder were measured according to (AOAC 1990 a,b, AOAC, 2000). And the oil was extracted with hexane over $8 \mathrm{~h}$ in a Soxhlet apparatus was carried out according to a method of (Besbes et al., 2004a).The obtained pit oils were drained and then The extracted oils were stored at- $20^{\circ} \mathrm{C}$ until further analysis.

\section{Fatty acid analysis}

The evaluation of fatty acids of the extracted date seed oils were determined by Gas Chromatography according to methods for preparing the FAME from fats and oils (ES, ISO 5508 (1990).

\section{Oil chemical properties}

The extracted date seed oils were analyzed for acid value which was determined as described by the British Standards Institution (BS EN ISO 660: 2009).Total phenols in date seed oil were determined colorimetry at $725 \mathrm{~nm}$ with the Folin-Ciocalteau reagent as done by Gutfinger (1981). Carotenoid and chlorophyll were calorimetrically determined as described (Minguez-Mosquera et al., 1991).

Mixtures of soybean oil and date seeds oil preparation

Soybean oil was kindly provided from the (Nile oil and detergents company, Sohage, Egypt) the oil was clear, crude and did not have any synthetic antioxidants used as a control sample,BHT was added to crude soybean oil at a rate of $250 \mathrm{ppm}$, three different levels (5\%,10\% and $15 \%)$ of date seed oils from all cultivars individually were mixed with soybean crude oil and stirred at room temperature, the produced mixture were used for oxidative stability measurement(Rancimat).

\section{Oxidative stability}

Oxidative stability was evaluated by the Rancimat method. Stability was expressed as the oxidation induction time measured with the Rancimat 679 apparatus (Metrohm AG, Herison, Switzerland). The induction time was defined as the time necessary to reach the inflection point of the conductivity curve (Halbault et al., 1997).

\section{Results and Discussion}

Physical and chemical characteristics of the date fruits

In the present study, fruits from three cultivars 
of date palm: 'Hayani','Sewi' and 'Sakouti', grown in southern Egypt were evaluated for the fruit characteristics, as an indication of the fruit ripening stage (Fig. 1). Physical and chemical measurements of the fruit such as fruit, flesh, pit weight, flesh/fruit, pit/fruit percentage and flesh/ pit ratio are presented in Table 1. Fruit and pit weight of 'Hayani' was significantly the highest followed by 'Sewi' and 'Sakouti'. 'Sewi' fruit had the highest pit weight while the 'Hayani' had highest flesh weight. That eventually resulted in significant differences between cultivars, as it was the highest for flesh/fruit (91.5\%), and pit/ fruit $(14.5 \%)$ in 'Sakouti' and 'Sewi' respectively. 'Sewi' cultivar had a bigger pit that reflected on the value of the Flesh/pit ratio to be the lowest (5.95) compared to the other cultivars (Table 1). This data agreed with previous reports that date fruit characteristics depends on variety and environmental conditions (Goda, 1990 and AlHooti et al., 1995).

Total soluble solids and acidity of the fruits are important evaluations of fruit ripening to determine the postharvest quality (Kader et al., 1998). Results of the chemical analysis such as: titratable acidity and $\mathrm{pH}$ and TSS of the date pulp juice, moisture contents of the fresh fruit and pit and pit powder as well as oil and ash contents of the pit powder is presented in Table 1. TSS of date pulp juice was highest in 'Sakouti' (67.3) followed by 'Sewi' and 'Hayani' that had (57.9, 52.2) respectively. The $\mathrm{pH}$ and the titratable acidity for the 'Sakouti' juice $(0.69,6.2)$ was significantly different from the other cultivars; $(0.46,7.53)$ for 'Hayani' and $(0.39,7.29)$ for 'Sewi' (Table 1). These values were in the normal range for the fresh date fruit at harvest time of all cultivars.

Moisture content and ash of the fruit flesh was not different within the studied cultivars. On the other hand the pit moisture was $(30.7,31.2,29.8)$ for 'Hayani', 'Sewi' and 'Sakouti' respectively, which means that the net weight of dried powder is roughly $69.3-68.8,70.2$ ) for the three cultivars (Table 1). The oil contents of the pit powder of 'Hayani' cultivars was the highest $(10.6 \%)$ while there were no differences between the other two cultivars 'Sewi' and 'Sakouti' (8.22, 8.20\%) respectively. This substantial amount of oil can be extracted and utilized in different food processing (Nehdi et al., 2010).

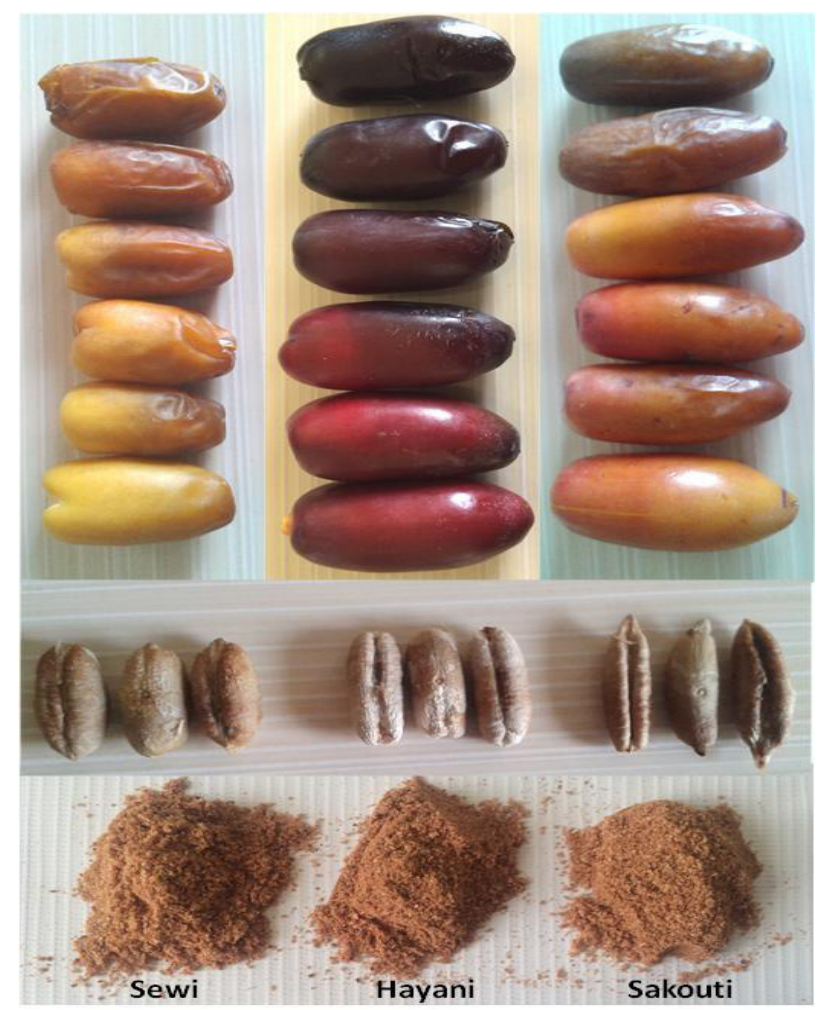

Fig. 1. Fruit, pit and pit powder of three date palm cultivars 'Sewi', 'Hayani' and 'Sakouti' 
TABLE 1. Physical characteristic of date palm fruit

\begin{tabular}{lccc}
\hline \multirow{2}{*}{ Fruit characteristics } & \multicolumn{1}{c}{ Cultivar } & Sakouti \\
\cline { 2 - 4 } & Hayani & Sewi & $11.5+0.39 \mathrm{c}$ \\
\hline Fruit weight (g) & $14.9+0.41 \mathrm{a}$ & $13.0+0.44 \mathrm{~b}$ & $10.4+0.35 \mathrm{~b}$ \\
Flesh weight (g) & $13.40+0.41 \mathrm{a}$ & $11.1+0.43 \mathrm{~b}$ & $0.97+0.04 \mathrm{~b}$ \\
Pit weight (g) & $1.49+0.06 \mathrm{ab}$ & $1.86+0.04 \mathrm{a}$ & $91.5+0.63 \mathrm{a}$ \\
Flesh/fruit (\%) & $89.4+0.62 \mathrm{~b}$ & $84.8+0.61 \mathrm{c}$ & $8.5+0.22 \mathrm{c}$ \\
Pit/fruit (\%) & $10.1+0.44 \mathrm{~b}$ & $14.5+0.51 \mathrm{a}$ & $10.8+0.31 \mathrm{a}$ \\
Flesh/pit ratio & $9.23+0.5 \mathrm{a}$ & $5.95+0.21 \mathrm{~b}$ & $67.3+0.32 \mathrm{a}$ \\
\hline Chemical characteristics of the date palm fruit & & & $0.69+0.03 \mathrm{a}$ \\
\hline TSS (Total soluble solids) & $52.2+0.57 \mathrm{c}$ & $57.9+0.37 \mathrm{~b}$ & $6.02+0.01 \mathrm{~b}$ \\
Acidity & $0.46+0.03 \mathrm{~b}$ & $0.36+0.01 \mathrm{~b}$ & $47.6+0.47 \mathrm{~b}$ \\
PH & $7.53+0.01 \mathrm{a}$ & $7.29+0.02 \mathrm{a}$ & $29.8+0.33 \mathrm{a}$ \\
Flesh moisture (\%) & $49.1+0.61 \mathrm{a}$ & $50.1+0.53 \mathrm{a}$ & $3.80+070 \mathrm{a}$ \\
Fresh pit moisture (\%) & $30.7+0.50 \mathrm{a}$ & $31.2+0.48 \mathrm{a}$ & $1.13+0.02 \mathrm{a}$ \\
Pit powder moisture (\%) & $4.10+0.08 \mathrm{a}$ & $3.10+0.10 \mathrm{a}$ & $8.20+0.33 \mathrm{~b}$ \\
Pit powder ash (\%) & $1.44+0.02 \mathrm{a}$ & $1.72+0.04 \mathrm{a}$ & $8.22+0.21 \mathrm{~b}$ \\
Pit oil content (\%) & $10.6+0.18 \mathrm{a}$ &
\end{tabular}

Values are the mean \pm standard error, $\mathrm{n}=50$.

\section{Chemical characteristics of date seed oil}

Chemical properties of the extractable oil from date seed are presented in Table 3. Date seed oils showed low acid value as 'Sewi' oil date seedhadthe lowest acid value 1.75 and 'Sakouti' 1.78 while 'Hayani' the highest acid value 1.90 . The low free fatty acids (FFA) content of the oil indicated that it is edible and could have a long shelf life as low acidity value indicates higher stability of the oil (Boukouada and Yousfi, 2009).

The phenolic content of oils assessing the quality of oil as it is correlated with color and the shelf-life of oil, in particularly its resistance to oxidation (Cheikh-Rouhou et al., 2006). In this study, date seed oil of all cultivars showed substantial content of total phenols, the content of total phenolic varied between cultivars. 'Sewi' had the highest content of phenolic compounds that $183.92 \mathrm{mg}$, while 'Hayani' and 'Sakouti' had 30.98 and $36.95 \mathrm{mg}$ respectively. Our results were consistent with that reported by (Besbes et al., 2004b). They reported that phenolic content in date seed oil was relatively high compared to most edible oils except for olive oil, which is considered to be a rich source of phenolic compounds in the Mediterranean diet (Nissiotis and Tasioula-Margari, 2002). This means that date pits oil is good source of phenolic compounds and this content varied according to cultivars due to the genetic variation (Saafi et al., 2008). The differences in chemical composition of both date flesh and seed might be due to the variability of the cultivars and also climatic conditions. Date seed oil had been shown to be rich in the content of polyphenols (Caponio et al., 1999 and Ali \& El Anany, 2012).

Color of date seed oil was varied from yellow for both 'Hayani' and 'Sakouti' to intense yellow for 'Sewi', these remarks indicates the presence of a sensible quantity of carotenoids in oils which is responsible for the yellow color of the date seed oil. The color of date seed oil varies from green-yellow to brown-yellow(Boukouada and Yousfi, 2009) or pale-yellow and it is semi-solid (Devshony et al., 1992). Significant quantity of carotenoid pigment in date seed oil and it makes its color a very intense yellow made it more yellow-colored than soybean oil, sunflower oil, olive oil and corn oil (Saafi et al., 2008). Carotenoids content of date seed oils in this study varied from $(33.5 \mathrm{mg} / \mathrm{kg}$ to $88.5 \mathrm{mg} / \mathrm{kg}$ ) (Table 2). $\beta$-Carotene is the major carotenoid in date seed oil of the 18 date varieties cultivated in the UAE and ranged between $1.18 \mathrm{mg}$ and $2.68 \mathrm{mg} / 100 \mathrm{~g}$ (Habib et al.,2013). Carotenoids are beneficial as they simulate the appearance of butter (Oomah et al., 2000). 
TABLE 2. Chemical characteristics of the date seed oil

\begin{tabular}{cccc}
\hline Oil quality index & \multicolumn{2}{c}{ Cultivar } \\
\hline & Hayani & Sewi & Sakouti \\
\hline Acidity $(\mathrm{mg} \mathrm{KOH} \mathrm{g-1)}$ & $1.9 \pm 0.04 \mathrm{a}$ & $1.75 \pm 0.04 \mathrm{a}$ & $1.78 \pm 0.02 \mathrm{a}$ \\
Phenolic $(\mathrm{mg} / 100 \mathrm{~g})$ & $30.1 \pm 0.21 \mathrm{~b}$ & $183.92 \pm 0.51 \mathrm{a}$ & $36.95 \pm 0.13 \mathrm{~b}$ \\
Chlorophyll $(\mathrm{mg} / \mathrm{kg})$ & $2.17 \pm 0.03 \mathrm{a}$ & $1.65 \pm 0.05 \mathrm{a}$ & $1.47 \pm 0.02 \mathrm{a}$ \\
Carotenoid $(\mathrm{mg} / \mathrm{kg})$ & $33.5 \pm 0.31 \mathrm{c}$ & $88.5 \pm 0.40 \mathrm{a}$ & $60.2 \pm 0.34 \mathrm{~b}$ \\
State at room temperature & liquid & liquid & liquid \\
\hline
\end{tabular}

TABLE 3. Fatty acid composition of date seed oil

\begin{tabular}{|c|c|c|c|}
\hline \multirow{2}{*}{ Fatty acid } & \multicolumn{3}{|c|}{ Cultivar } \\
\hline & Hayani & Sewi & Sakouti \\
\hline Caprylic C8:0 & ND & 0.42 & ND \\
\hline Capric $\quad$ C10:0) & 0.44 & 0.52 & 0.35 \\
\hline Lauric $\quad \mathrm{C} 12: 0$ & 21.8 & 21.37 & 18.78 \\
\hline Myristic C14:0 & 11.85 & 10.75 & 11.3 \\
\hline Palmitic C16:0 & 11.64 & 10.52 & 11.31 \\
\hline Stearic C18:0 & 2.88 & 3.25 & 2.89 \\
\hline Oleic $\quad$ C18:1 $\omega 9$ & 41.9 & 44.03 & 44.61 \\
\hline 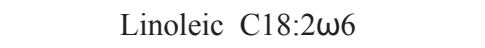 & 8.19 & 7.56 & 9.14 \\
\hline Linolenic C18:3 & 0.06 & 0.03 & 0.2 \\
\hline 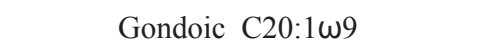 & 0.35 & 0.5 & 0.4 \\
\hline Behenic (C22:0) & 0.36 & 0.33 & 0.30 \\
\hline SFA(saturated fatty acid) & 48.97 & 47.16 & 44.93 \\
\hline UFA (unsaturated fatty acid) & 50.50 & 52.12 & 54.35 \\
\hline MUFA(Mono unsaturated fatty acid) & 42.25 & 44.53 & 45.01 \\
\hline PUFA(poly unsaturated fatty acid) & 8.25 & 7.59 & 9.34 \\
\hline Unsaturated/Saturated & 1.03 & 1.10 & 1.20 \\
\hline Oliec/Linoliec & 5.11 & 5.82 & 4.88 \\
\hline
\end{tabular}

Green pigments, particularly chlorophyll content was detectable for all the studied varieties. The highest content of chlorophyll was for 'Hayani' $(2.17 \mathrm{mg} / \mathrm{kg})$ and the lowest was for 'Sakouti' $(1.47 \mathrm{mg} / \mathrm{kg})$ while the content for 'Sewi' was $(1.65 \mathrm{mg} / \mathrm{kg})$.

Fatty acid composition of date seed oil

The fatty acid compositions of date pits oils from the three studied cultivars are presented in Table 3. The fatty acid compositions of all the cultivars are very similar. The 6 major fatty acids identified in all cultivars were oleic acid

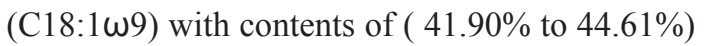
followed by lauric acid $(\mathrm{C} 12: 0)$ at $(18.78 \%$ to $21.80 \%)$, myristic acid (C14:0) at $(10.75 \%$ to $11.85 \%)$, palmitic acid $(\mathrm{C} 16: 0)$ at $(10.52 \%$ to
$11.64 \%)$, linoleic acid $(\mathrm{C} 18: 2 \omega 6)$ at $(7.56 \%$ to $9.14 \%)$, and stearic acid (C18:0) at $(2.88 \%$ to $3.25 \%$ ). Monounsaturated oleic acids, which are the major acids in date seed oils and olive oil, have been shown to reduce the risk of cardiovascular disease (Mart'ınez-Gonz'alezet al., 2015).This results is agreed with those reported by (Akbari et al., 2012,Nehdi et al., 2018).In general, the ratio of Unsaturation/Saturation (US/S) fatty acids ranged (1.03-1.20). The cultivars in this study can be classified as oleic-lauric oils.

Oxidative stability of date seed oil and their mixtures with soybean oil

Data for the measurements of the oxidation stability of oils by rancimat for soybean and all studied cultivars, as well as the treatments at 
different levels $(5,10$ and 15\%) are presented in Fig. 2. Generally, the stability of the oil extracted from date seed was higher than the crude soybean oil. The induction time for the soybean oil was $5.3 \mathrm{~h}$, while the extracted oil from date seed of different cultivars was $19.7,20.7$ and $25.0 \mathrm{hr}$ for 'Hayani', 'Sakouti'and 'Sewi' oil, respectively.

Addition of synthetic antioxidant Butylated hydroxyl toluene (BHT) to the soybean oil increased the stability as the induction time increased from 5.3 to $12.1 \mathrm{hr}$. Addition of date seed oil to soybean oil at three different levels generally increased the induction time positively linked to increase the oxidative stability of the oil. Oil from 'Sewi' cultivar at $15 \%$ was the best treatment as it significantly increased the induction time $(16.2 \mathrm{hr})$ more than BHT. The $10 \%$ 'Sewi' oil $(13.1 \mathrm{hr})$ and $15 \%$ 'Sakouti' oil treatments $(12.4 \mathrm{hr})$ had similar effect as BHT and higher effect than the other treatments. Oil of 'Hayani' cultivar did increase the induction time of the soy bean but not as much as the other treatments. The present study results agreed with previous reports that the seed oil extracted from different date palm cultivars recorded induction time of 21.8 -22.9 hr (Nehdi et al., 2018). The level of monounsaturated fatty acids, carotenoids content and phenolic compounds that transferred from the seed into the extracted oil, may explain the high induction time of date seed oils compared to the other vegetable oil. The higher rancimat of date seed oil inversely proportional to polyunsaturated fatty acids contents (PUFA) detected in the date seed oil (Gharibzahedi et al., 2013). The oxidative stability of date seed oil was high also due to the low content of linoleic and lack of linolenic as a PUFA acid (Biglar et al., 2012). However, some expected lipophilic components of the date seeds could be extracted into the oils and caused the oxidative stability to be increased.

The date seed extracted oil in this study falls within the definition of CODEX STAN. of edible vegetable oils that are known as the foodstuffs which are composed primarily of glycerides of fatty acids being obtained only from vegetable sources. They may contain small amounts of other lipids such as phosphatides, of unsaponifiable constituents and of free fatty acids naturally present in the fat or oil. Also, MPOB (2014) approved that vegetable oils, animal fats or a mixture of both can serve as the frying medium. In order to select the frying medium suitable for deepfrying, the important attributes to be considered are the ability of the fats/oils to withstand the high temperature of deep frying as well as stable against the oxidation and polymerisation. The oil must have a high resistance to oxidation and gumming, low free fatty acid rise and smoking, low rate of foaming, low rate of darkening, low melting point (except for special purpose) and

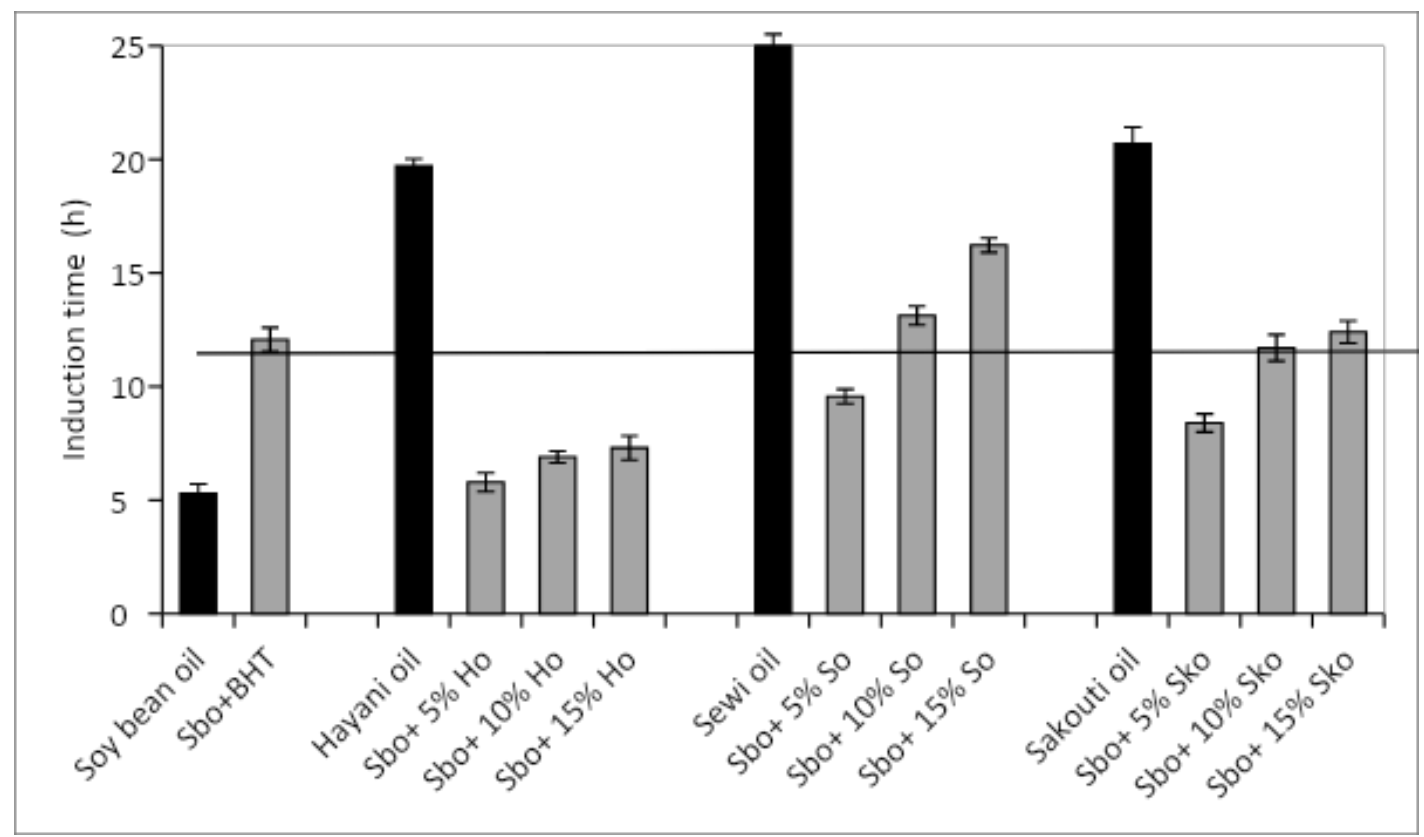

Fig. 2. Induction period of date seed crude oils as well as soybean crude oil, and the treatment of soybean oil with BHT or different levels of date seed oils measured by Rancimat test. \# Sob =soybean oil, BHT= Butylated hydroxyl toluene, $\mathrm{Ho}=$ Hayani oil, $\mathrm{So}=$ Sewi oil, Sko= Sakouti oil

Egypt. J. Food Sci. 47, No.1(2019) 
nutritionally good fatty acid composition.A blend of palm oil and vegetable oils such as groundnut oil, cottonseed oil and soyabean oil enhances the stability of the liquid vegetable oils (MPOB, 2014). The extracted oils in the present study cover successfully MPOB criteria's.

CODEX Comitee on Fats and oils (CCFO), 2017, agreed to request CAC38 to approve a new work on the revision of the Standard for Named Vegetable Oils (CODEX STAN, 210-1999) to include a new category named "Palm Oil - High Oleic Acid" containing 48-58 \% oleic acid. The committee noted that ranges for percent oleic acid (C18:1) in mid and high oleic acid oils contained in the Standard for Named Vegetable Oils (CODEX STAN 210-1999) are 43.1 - 71.8 Mid Oleic Acid Sunflower Seed Oil -75 - 90.7 - High Oleic Acid Sunflower Seed Oil, 70.0 - 83.7 High Oleic Acid SafflowerSeed Oil - palm oil containing 48-58\% oleic acid be called "Palm Oil - Mid Oleic Acid "according to these reports the extracted oils in this study could be named a Mid Oleic Acid oils.

The requirements in the Standard for Named Vegetable Oils (CODEX STAN) are to ensure consumer protection in terms of food safety and authenticity of the products. Further studies are needed to ensure that the extracted oil from date palm seed is healthy and safe for human consumption.

\section{Conclusion}

The extraction of date oils from seed as by-product of date industry may contribute in reuse some of the date seed waste in many of date-producing countries. Date seed oils had high monounsaturated fatty acids, carotenoids and phenolic compounds contents than other commonly consumed oils, indicatingthe higher oxidative stability. This high oxidative stability makes it great natural additive to the other crude vegetable oil to improve its heat stability, and might be a promising substitute for the commercially used synthetic antioxidant such as BHT. Our results suggest that the synthetic antioxidant could be safely replaced by natural source of antioxidant found in date seed oil especially from Sewi and 'Sakouti' cultivars.

\section{Acknowledgments}

The authors would like to thank South Valley University, College of Agricultural, Qena, Egypt for the financial support of the research. We are also grateful to the Agriculture Research Center,
Food Technology Research Institute, Oils and Fats Research Department, Egypt, for providing the oil fatty acid profile analysis.

\section{Funding Statements}

This research is funded by College of Agriculture, South Valley University, Qena, Egypt.

\section{Conflict of Interest}

The authors declare that there is no conflict of interest.

\section{$\underline{\text { References }}$}

Abdul Afiq, M.J. R., Abdul Rahman, Y.B., Che Man, H.A., AL-Kahtani, and Mansor,.T.S.T. (2013) Date seed and date seed oil.J.Inter. Food Res.,20 (5), 2035-2043.

Akbari, M. 1., Razavizadeh, R., Mohebbi, G. H. and Barmak, A. (2012) Oil characteristics and fatty acid profile of seeds from three varieties of date palm (Phoenix dactylifera) cultivars in BushehrIran. J. Afric. Biotech., 11(57), 12088-12093.

Al-Hooti, S. N., Sidhu, J. S. and Qabazard, H.(1995) Studies on the physico-chemical characteristics of date fruits of five UAE cultivars at different stages of maturity - Plant Foods for Human Nutrition. Arab Gulf. J. Sci. Res., 13 (3), 553-569.

Ali and El Anany (2012) Physicochemical Studies on Sunflower Oil Blended with Cold Pressed Tiger Nut Oil, during Deep Frying Process. J. Food Process Technol., 3,88.

AOAC (1990a) Official Methods of Analysis of The Association of Official Analytical Chemists $\left(15^{\text {th }}\right.$ Ed) edited by K. Helrich Washington DC: AOAC.

AOAC (1990b) Official Methods of Analysis of The Association of Official Analytical Chemists. Arlington, USA: Association of Official Analytical Chemists.

AOAC (2000) Official Methods of Analysis of The Association of Official Analytical Chemists (1 $7^{\text {th }}$ ed.) edited by K .HelrichWashington., DC,AOAC.

Bandak, G. E.K., Dermesonlouglou, P.S., Taoukis and Oreopoulou,.V. (2011) Antioxidant effect of Majorana syriaca extract in bulk corn oil and o/w emulsion after applying high hydrostatic pressure. J.Food Chem.,125,1166-1170.

Besbes, S., Blecker, C.,Deroanne,C., Drira,N. and Attia, H. (2004a) Date Pits: Chemical Composition 
and Characteristic Profiles of the Lipid Fraction. $J$. Food Chem., 84 (4),577-584.

Besbes, S., Blecker, C., Deroanne, C., Bahloul, N., Lognay, G., Drira, N., et al. (2004b). Phenolic, tocopherol and sterol profiles. J. Food Lipids, 11, 251-265.

Biglar, M., Khanavi,M., Hajimahmoodi,M., Hassani,S., Moghaddam,G., Sadeghi,N.and Oveisi,M. (2012) Tocopherol Content and Fatty acid Profile of Different Iranian Date Seed Oils. Iranian $J$. Pharmaceutical Res., 11 (3), 873-878.

Bouaziz, M., Fki, I., Jemai, H., Ayadi, M. and Sayadi, S. (2008) Effect of storage on refined and husk olive oils composition: stabilization by addition of natural antioxidants from Chemlali olive leaves. $J$. Food Chem. 108, 253-262.

Boukouada, M. and Yousfi, M. (2009) Phytochemical study of date seeds lipids of three fruits (Phoenix dactylifera L.) produced in Ouargla region. Annales de la Faculté des Sciences et Sciemces de I'Ingénieur 1, 66-74.

Bozkurt, H. (2006) Utilization of natural antioxidants: green tea extract and Thymbravspicata oil in Turkish dry-fermented sausage. Meat Sci.,73,442450 .

Caponio, F., Alloggio, V. and Gomes, T. (1999). Phenolic compounds of virgin olive oil: Influence of paste preparation techniques. J. Food Chem., 64, 203-209.

CheikhRouhou, S., Hentati, B, Besbes, S., Blecker, C.,Deroanne, C. and Attia, H. (2006) Chemical composition of and lipid fraction characteristics of Aleppo pine (Pinus halepensis) mill seeds cultivated in Tunisia. J. Food Sci. and Technol. Inte., 12 (5), 407-416.

Devshony, S., Eteshola, A. and Shani, A. (1992) Characterisation and some potential application of date palm (Phoenix dactylifera L.) seeds and seeds oil. J. Ame. Oil Chem. Soci., 69, 595-597.

ES ISO 5508 (1990) Animal and vegetable fats and oils analysis by gas chromatography of methyl esters of fatty acids.

Gado, G. B. A. (1999) Chemical and technological studies on some local date varieties. MSc. Thesis, Fac. Agric, Food, Sci. and Technol. Minia .Univ. Egypt.

Gharibzahedi, S.M.T., Mousavi, S.M., Hamedi, M., Rezaei, K., Khodaiyan, F. (2013) Evaluation of physicochemical properties and antioxidant activities of Persian walnut oil obtained by several extraction methods. Ind. Crop Prod., 45, 133- 40.

Grootveld, M., Silwood, C. J.L., Addis, P., Claxson, A., Serra, B.B. and Viana, M.(2001) Health effect of oxidized heated oils. J. Food Service, 13 (1),41-55.

Gutfinger, T. (1981) Polyphenols in olive oils. J. Am. Oil Chem. Soc. 58, 966-968.

Habib, H. M., Kamal, H., Ibrahim, W. H. and AlDhaheri, A. S. (2013) Carotenoids, fat soluble vitamins and fatty acid profiles of 18 varieties of date seed oil. J. of Industerial Crops and Products, 42, 567-572.

Halbault, L., Barbe, C., Aroztegui, M. and La Torre, C. (1997) Oxidative stability of semi-solid excipient mixtures with corn oil and its implication in the degradation of vitamin A. Int. J. Pharmaceutics. 147,31-41.

Herchi, W., Kallel,H. and Bouhkchina, S.(2014) Physicochemical properties and antioxidant activity of Tunisian date palm (Phoenix dactylifera L.) oil as affected by different extraction methods. J.Food Sci. Technol., Campinas. 34 (3),464-470.

Kader, A. A., Zagory,D., Kerbel,E. L. and Wang, C. Y.(1989) Modified atmosphere packaging of fruits and vegetables. Critical Rev. J. Food Sci. Nutr. 28 (1), 1-30.

Leonardis, A., Macciola,V., Lembo,G., Aretini,A. and Nag, A. (2007) Studies on oxidative stabilisation of lard by natural antioxidants recovered from oliveoil mill wastewater. J. Food Chem. 100, 998-1004.

Mart'ınez-Gonz'alez, M.A., Salas-Salvad'o, J., Estruch, R., Corella, D., Fit'o, M., Ros, E., Investigators, P. (2015) Benefits of the Mediterranean diet: insights from the PREDIMED study. Prog. Cardiovasc Dis., 58,50-60.

Minguez-Mosquera, M. I., Rejano-Navarro, L., Gandulrojas, B.,Sanchez Gomez, A. H. and Garrido-Fernandez, J. (1991) Color pigment correlation in virgin olive oil. $J$. of the American Oil Chem. Soci., 68 (2), 332-336.

Nehdi, S ., Omrib, M.I and Khalil, S.I (2010) Characteristics and chemical composition of date palm (Phoenix canariensis) seeds and seed oil. J. Al-Resayesa Industrial Crops and Products, 32,360-365.

Nehdi,I.A., Sbihi,H.M., Tan,C.P., Rashid, U. and AlResayes, S.I. (2018) Chemical composition of date 
palm (phoenix dactylifera L.) seed oil from six saudi arabian cultivars. J. of Food Sci. 83, (3), 624630.

Nissiotis, M., and Tasioula-Margari, M. (2002) Changes in antioxidant concentration of virgin olive oil during thermal oxidation. J. Food Chem. 77, 371-376.

Oomah, B.D., Ladet, S., Godfrey, D.V., Liang, J. and Girald, B., (2000) Characteristics of raspberry (Rubisidaeus L.) seed oil.J. Food Chem.,69, 187193.

Paul, S. and Mittal,G. S. (1997) Regulating the use of degraded oil/fat in deep-fat/oil food frying. J.Crit. Rev. Food Sci. Nutr. 37 (7),635-662.

Saafi, E.B., Trigui, M., Thabet, R., Hammami, M. and Achour, L. (2008) Common date palm in Tunisia: chemical composition of pulp and pits. International. J. of Food Sci., and Technol.,43 (11), 2033-2037.

Sarkar, A. (2016) Natural Antioxidants - The Key to Safe and Sustainable Life. Inter. J. Latest Trends Engin. Technol., 6 (3),460-466.

Shahidi, F. (2005) Bailey's industrial oil and fat products. John Wiley \& Sons, New Jersey.
Shebis, Y., Iluz, D., Kinel-Tahan,Y., Dubinsky, Z. and Yehoshua,Y. (2013) Natural Antioxidants: Function and Sources. J. Food Nutr. Sci. 4,643-649.

Suja, K. P., Abraham, J.T., Thamizh, S. N., Jayalekshmy, A. and Arumughan, C.(2004) Antioxidant efficacy of sesame cake extract in vegetable oil protection. J. Food Chem. 84, 393-400.

Taghvaei, M . and Jafari, S. M.(2015) Application and stability of natural antioxidants in edible oils in order to substitute synthetic additives. J. Food Sci. Technol., 52 (3),1272-1282.

Taha, E., Abouelhawa,S., El-Geddawy,M., Sorour,M., Aladedunye,F. and Matthäus,B (2014) Stabilization of refined rapeseed oil during deep-fat frying by selected herbs. Eur. J. Lipid Sci. Technol.,116, 771779.

Yanishlieva, N.V. and Marinova, E.M.(2001) Stabilisation of edible oils with natural antioxidants. European. J. Lipid Sci. Technol.,103,752-767.

Young, I. S. and Woodside, J. V.(2001) Antioxidants in health and disease. J. Clin Patholology, 54,176186.

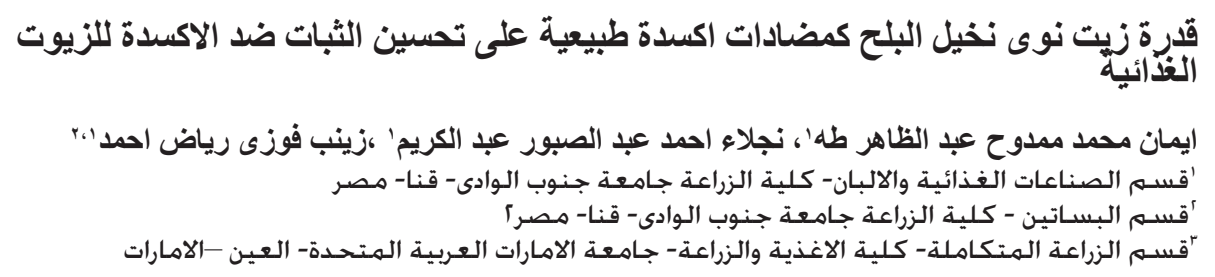

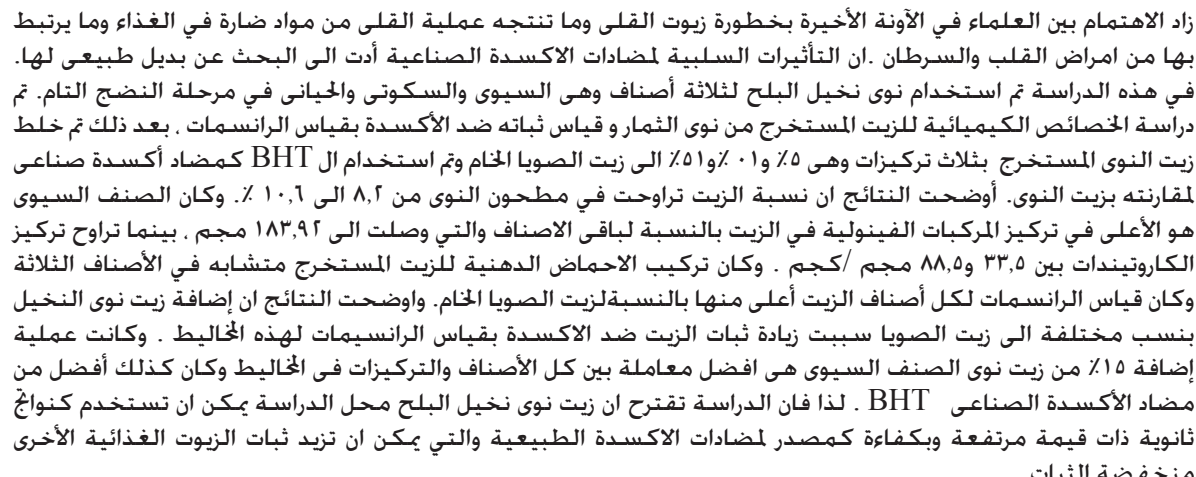

Egypt. J. Food Sci. 47, No.1 (2018) 